\title{
Pollen-limited seed set in pods of tamarind (Tamarindus indica L.)
}

\author{
K.R. Thimmaraju, V. Bhaskar and K. Usha \\ University of Agricultural Sciences, Gandhi Krishi Vignana Kendra, Bangalore 560 065, India
}

\section{Introduction}

A negatively skewed distribution of seeds per pod, where the frequency of manyseeded pods is higher than that of the few seeded ones, is a common feature of a majority of the multiovuled species (Lee and Bazaaz, 1982), However, disturbances of this negatively skewed distribution have been reported for certain other species. The adaptive reasons for and mechanisms causing such deviations are less well known. In this paper, we have analyzed 3 factors causing positively skewed distribution (PSD) of seeds per pod in $T$. indica: 1) resource limitation, 2) post-fertilization abortion of seeds, and 3) pollen grain limitation.

\section{Materials and Methods}

Tamarindus indica L. (Caesalpinae) is a tropical tree cultivated for the pulp of the fruit, which is used in culinary preparations. It exhibits varied patterns of seed distributions per pod of which PSD is the most common. Data were gathered from 4 tamarind trees in and around Gandhi Krishi Vignana Kendra Campus of the University of Agricultural Sciences, Bangalore, India, using 50 flowers for each set of observations: 1) pollen grains/stigma of intact and abscised flowers, 2) number of fertilized ovules, 3) percentage of flowers set into fruits, and 4) resource limitation: selected branches of approximately equal size were defoliated to an extent of $25(n=10), 50$ $(n=10)$ and $75 \%(n=10)$ and fruit set in these was compared with control branches; 5 ) effect of pollen quality: flowers $(n=50)$ were either self-pollinated, artificially crossed with pollen from different trees or allowed to pollinate naturally. The seed set percentage of these was compared.

\section{Results}

Pod and seed set were low in tamarind; about $25 \%$ of the flowers set pods and most contained few (1-4) seeds (Fig. 1). Resource limitation did not cause this reduction in pod setting and seed filling; even $50 \%$ defoliation of leaves did not reduce the pod-setting percentage, although $75 \%$ defoliation did cause significant reduction (11.5\%).

In tamarind, as in other species (Wilson and Schemske, 1980), there is selective abortion of pods. The percent pods with many seeds reaching maturity is higher 


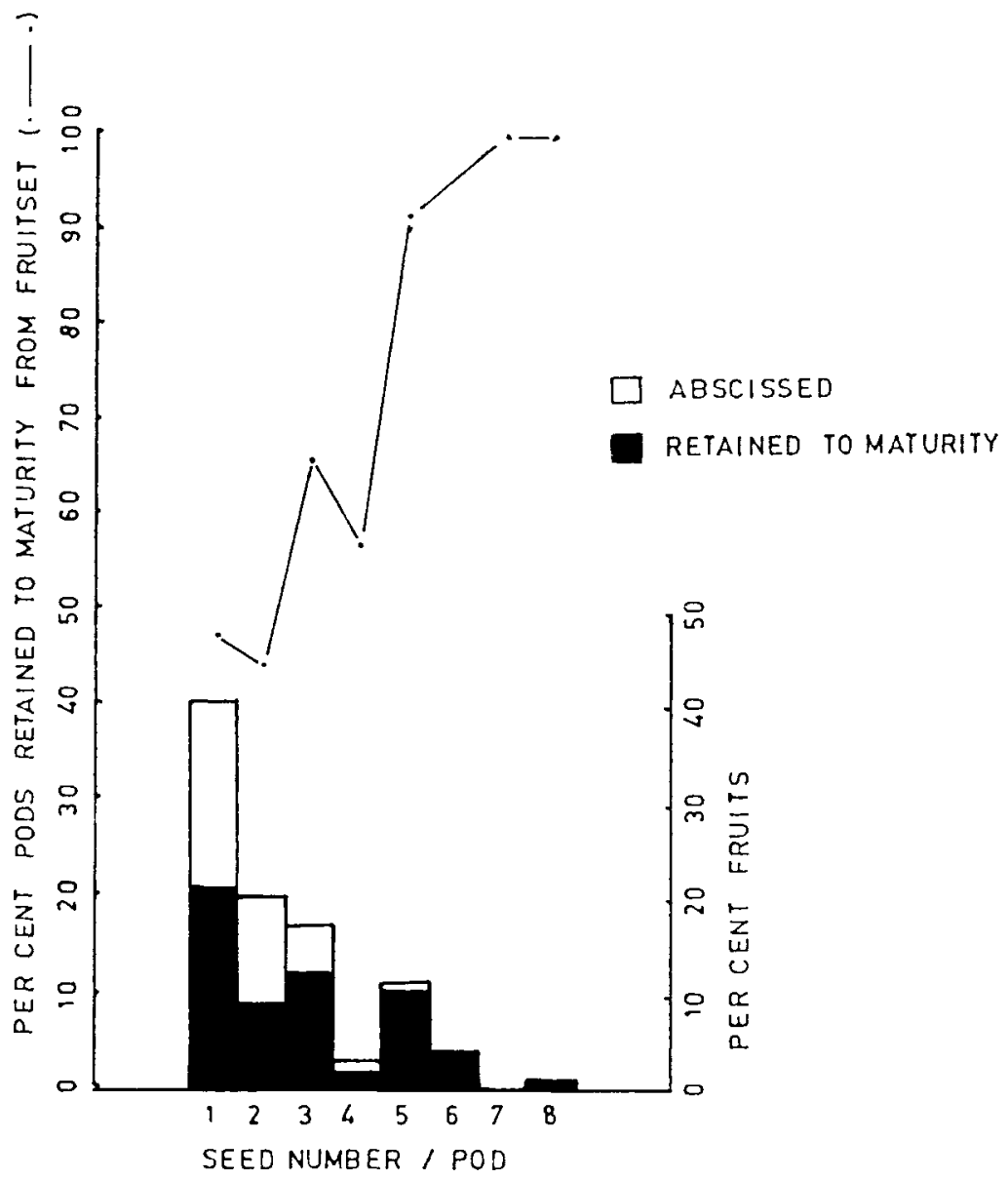

Fig. 1. The relationship between seed number/fuit and the percent abscission and retention.

than those with few seeds. Thus selective abortion does not cause the observed PSD.

In tamarind, the ovary contains 8-10 ovules and $40 \%$ of the flowers received more than 10 pollen grains. Hence pollen grain number limitation cannot explain the reduced seed set. However, until 15 pollen grains were deposited, the stigma did not seem to allow fertilization of ovules, afterwards, for the addition of every 3-4 pollen grains, an additional ovule was fertilized
(Fig. 2). This indicates the existence of pollen-stigma interactions. Such interactions can occur at 2 levels viz. 1) numberdependent inhibition of pollen grain germination (Ganeshaiah et al., 1986) and 2) partial incompatibility of pollen grains. Although cross-pollination did not affect the fruit set percentage, it significantly affected the number of seeds per pod. While self-pollinated pods showed a PSD, crossed pods showed a negatively skewed distribution of pods. This is suggestive 


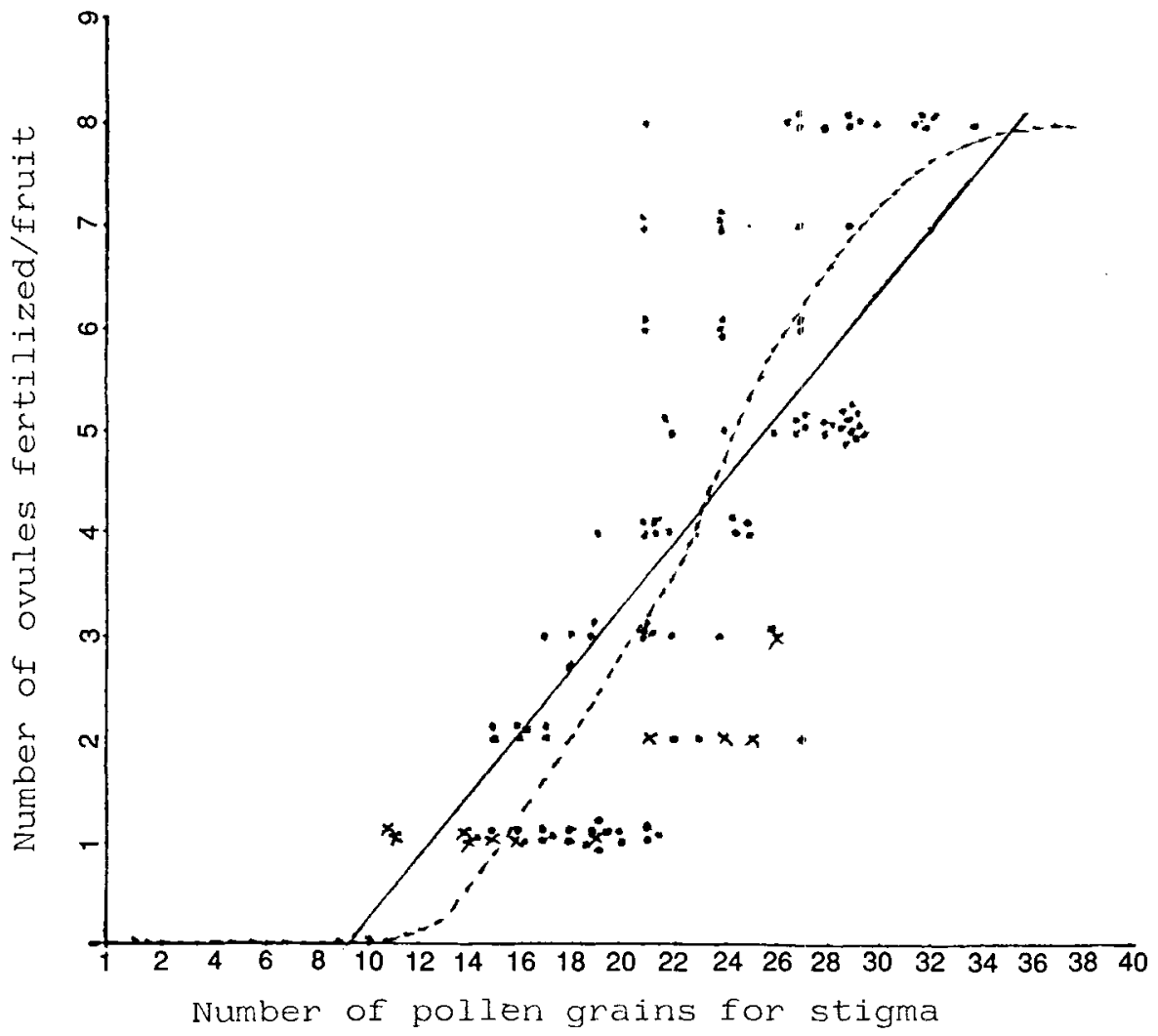

Fig. 2. Relationship between pollen grain number/stigma and number of ovules fertilized/fruit. $x$ : pollen/stigma in abscised flowers; $\bullet$ pollen/stigma in intact flowers. $r=0.72^{\star \star} ; y=0.31 x-3.04$.

of the existence of a certain amount of partial self-incompatibility (Table I).

\section{Discussion and Conclusion}

In tamarind, PSD appears not to be under the regulation of the maternal parent, but to be a consequence of genetic differences among the pollen grains.

Tamarind produces an average of 8-10 ovules among which very few generally develop into seeds. Failure of the rest of
Table I. The influence of self, cross- and openpollination on the percentage of fruits carried to maturity.

\begin{tabular}{ll}
\hline Pollination & \% pod set \\
\hline Open & $25.75 \pm 1.00$ \\
Self & $58.75 \pm 4.81$ \\
Cross & $82.37 \pm 4.70$ \\
\hline
\end{tabular}

the ovules to set seeds appears not to be due to the limitation of either pollen grains or resources. Post-fertilization abortion also does not explain PSD. However, the 
partial self-incompatibility appears to reduce the seed number per pod in self- and open-pollinated flowers, as indicated by the increased seed set in crossed over self- or open-pollinated flowers. It is not clear, whether the reduced seed number per pod in the self-pollinated flowers is due to the failure of pollen grains to germinate or due to the abortion of less competent zygotes. In either case, it can be concluded that the PSD is driven by the pollen grain differences.

\section{Acknowledgments}

The authors are grateful to the authorities of the University of Agricultural Sciences, Bangalore, India, for providing facilities to conduct this investigation. They are highly indebted to Dr. K.N. Ganeshaiah for critically reviewing the manuscript.

\section{References}

Ganeshaiah K.N. \& Umashankar R. (1988) Regulation of seed number and female initiation of mate competition by a pH-dependent proteinaceous inhibitor of pollen grain germination in Leucaena leucocephala. Oecologia 75, 110-113

Ganeshaiah K.N., Umashankar R. \& Shivashankar G. (1986) Stigmatic inhibition of pollen grain germination - its implication for frequency distribution of seed number in pods of Leucaena leucocephala (Zam) de wit. Oecologia $70,568-572$

Janzen D.H. (1982) Variation in average seed size and fruit seediness in a fruit crop of a gunacaste tree (Leguminoasae) Enterolobium cyclocarpum. Am. J. Bot. 69, 1169-1178

Lee T.D. \& Bazzaz F.A. (1982), Regulation of fruit and seed production in annual legume (Cassia fasciculata). Ecology 63, 1363-1373

Willson M.F. \& Schemske D.W. (1980) Pollinator limitation, fruit production and floral display in pawpaw (Asimina triloba). Bull. Torrey Bot. Club 107, 401-408 